\title{
Uncertainties of snow cover extraction caused by the nature of topography and underlying surface
}

\author{
Jun ZHAO*, YinFang SHI, YongSheng HUANG, JieWen FU \\ College of Geography and Environment Science, Northwest Normal University, Lanzhou 730070, China
}

\begin{abstract}
Manas River, the largest inland river to the north of the Tianshan Mountains, provides important water resources for human production and living. The seasonal snow cover and snowmelt play essential roles in the regulation of spring runoff in the Manas River Basin (MRB). Snow cover is one of the most significant input parameters for obtaining accurate simulations and predictions of spring runoff. Therefore, it is especially important to extract snow-covered area correctly in the MRB. In this study, we qualitatively and quantitatively analyzed the uncertainties of snow cover extraction caused by the terrain factors and land cover types using TM and DEM data, along with the Per (the ratio of the difference between snow-covered area extracted by the Normalized Difference Snow Index (NDSI) method and visual interpretation method to the actual snow-covered area) and roughness. The results indicated that the difference of snow-covered area extracted by the two methods was primarily reflected in the snow boundary and shadowy areas. The value of Per varied significantly in different elevation zones. That is, the value generally presented a normal distribution with the increase of elevation. The peak value of Per occurred in the elevation zone of 3,700-4,200 m. Aspects caused the uncertainties of snow cover extraction with the order of sunny slope>semi-shady and semi-sunny slope>shady slope, due to the differences in solar radiation received by each aspect. Regarding the influences of various land cover types on snow cover extraction in the study area, bare rock was more influential on snow cover extraction than grassland. Moreover, shrub had the weakest impact on snow cover extraction.
\end{abstract}

Keywords: Landsat TM; Normalized Difference Snow Index (NDSI); snow cover; uncertainty; Manas River Basin

Citation: Jun ZHAO, YinFang SHI, YongSheng HUANG, JieWen FU. 2015. Uncertainties of snow cover extraction caused by the nature of topography and underlying surface. Journal of Arid Land, 7(3): 285-295. doi: 10.1007/s40333-015-0044-x

Snow is the most active element in the climate system and the most sensitive to environmental change (Lopez et al., 2008). It has important effects on regional climate, natural environment and human activities. In the alpine mountains and arid regions, snowmelt provides freshwater for human well-being and agricultural production. The seasonal snow cover (one of the most significant input parameters for obtaining accurate simulations and predictions of spring runoff) and snowmelt (runoff) play essential roles in the regulation of spring runoff in the Manas River Basin (MRB), Xinjiang of China (Feng et al., 2000). The spatial distribution of snow cover is used as an input parameter in various hydrological and meteorological models.
Snow cover mapping is the primary basis for simulating snowmelt runoff and snow feedbacks in the climate system (Wang, 1999). Therefore, it is particularly important to accurately extract snow cover using remote sensing technology.

The Normalized Difference Snow Index (NDSI) is an indicator that monitors a wide range of snow conditions in a simple and effective manner. Since Hall et al. (1995) developed the SNOMAP algorithm for snow cover mapping by using NDSI, many scholars have measured snow cover in different regions (e.g. Xiao et al., 2001, 2002; Hao et al., 2008). Along with the development of remote sensing technology, a series of snow cover mapping products were developed

*Corresponding author: Jun ZHAO (E-mail: zhaojun@nwnu.edu.cn)

Received 2014-05-02; revised 2014-10-13; accepted 2014-11-19

(C) Xinjiang Institute of Ecology and Geography, Chinese Academy of Sciences, Science Press and Springer-Verlag Berlin Heidelberg 2015 
(Yang et al., 2013). However, these products have some inevitable uncertainties (Guo et al., 2004). Due to environmental interference and access limitations to information and processing devices during acquisition and processing of remote sensing data, transmission leads to the uncertainty of images and subsequent products (Congalton et al., 2008). The uncertainty will spread and cause new uncertainties in the analysis processes of remote sensing data. Taking the uncertainty of remote sensing data classification as an example, it is the result of both uncertainty propagation and uncertainty accumulation in data acquisition, processing and analysis processes (Liu et al., 2010). Recent years, many researchers studied and discussed the uncertainty of remote sensing information. For example, Maguire et al. (1994), Sinton (1996) and Gahegan and Ehlers (2000) proposed theories and methods for measuring the uncertainty of spatial information of remote sensing data. Using probability theory, fuzzy sets and rough sets, researchers also developed a series of indicators (e.g. probbility entropy and roughness) for measuring the uncertainty based on a pixel, object or image (Goodchild et al., 1992). These indicators are conducive to error tracking and uncertainty transfer. Arbia et al. (1999) analyzed the uncertainty of attributes measurement and location, and their interactions using the Geman and Geman's corruption Model. Most of other researchers mainly focused on surface parameter inversion (e.g. surface albedo and temperature), crops remote sensing monitoring and land use/cover classification (Liu et al., 2010). Furthermore, a small number of researchers analyzed the factors (e.g. solar radiation and topography) that affected the extraction of snow cover. For example, Li et al. (2011) analyzed the correlation between the snow-covered area changes during the year and the altitude, slope and aspect using TM images. Wang et al. (2011) analyzed the effects of sensor gain, atmospheric factors and terrain on snow cover extraction by NDSI. However, the uncertainty of extracting snow information by using NDSI was not quantitatively evaluated using uncertainty theory, methods and indicators. Therefore, the major objective of this study was to analyze the uncertainties of snow cover extraction caused by different terrain factors and land cover types in the MRB using Landsat TM data. This research is vital to improving the accuracy of snow cover extraction, which will provide a better reference for estimating the regional water resources.

\section{Study area}

The Manas River Basin (MRB; $43^{\circ} 27^{\prime}-45^{\circ} 21^{\prime} \mathrm{N}$, $\left.85^{\circ} 01^{\prime}-86^{\circ} 32^{\prime} \mathrm{E}\right)$ is located in the southern Junggar Basin (Fig. 1). Manas River extends approximately $400 \mathrm{~km}$ over an area of $5,773.66 \mathrm{~km}^{2}$ and is the longest inland river in the Junggar Basin. The climate of the high mountainous area (over 3,600 m) in the MRB is cold and wet, and the area is covered by snow all year. The annual average temperature is below $0^{\circ} \mathrm{C}$ and the average annual precipitation is more than 500 $\mathrm{mm}$. The mid-altitude region $(1,500-3,600 \mathrm{~m})$ is characterized by a cold temperate semi-arid climate. The average annual precipitation is $300-500 \mathrm{~mm}$ and the annual average temperature is approximately $2^{\circ} \mathrm{C}$. The average annual precipitation in the low mountain and hill regions is approximately $250 \mathrm{~mm}$ due to a temperate arid climate, and the annual average temperature is $5^{\circ} \mathrm{C}$. The plain region (elevation $<600 \mathrm{~m}$ ) is characterized by a temperate arid climate with the average annual precipitation of $150 \mathrm{~mm}$ and the annual average temperature of $6^{\circ} \mathrm{C}$. In the study region, the snow-covered area varies greatly during the hydrological years (Chen and Bao, 2011). Additionally, snow cover in the MRB is mainly distributed in the southern mountains with higher elevations and is relatively stable. However, snow cover distributed in the northern and middle mountain regions has distinct seasonal variations (Yuan et al., 1995).

\section{Data and methods}

\subsection{Data and processing}

\subsubsection{Remote sensing data}

In this study, we chose TM images because of its relatively high spatial resolution $(30 \mathrm{~m})$, which can provide more detailed information of snow cover and is more suitable for precisely monitoring snow in small watersheds. Based on the regional scale and accuracy needs of the research, we used TM images to explore 


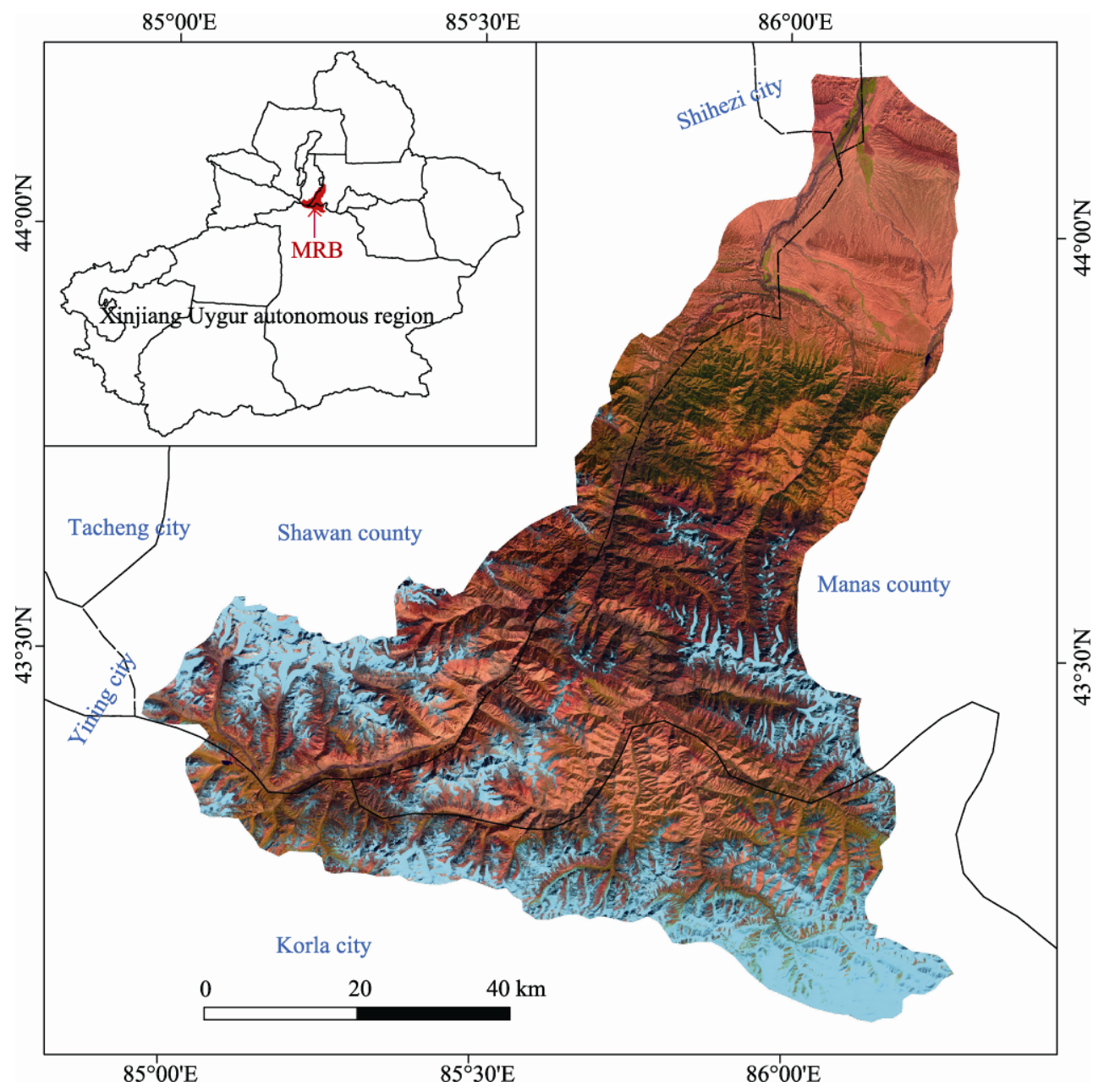

Fig. 1 Location of the Manas River Basin (MRB)

the effects of topography and land cover on snow data extraction using NDSI. The datasets were obtained from the Landsat TM sensor, which comprises seven wavebands with the wavelengths between 0.45 and $12.50 \mu \mathrm{m}$. The spatial resolution is $30 \mathrm{~m}$ for all of the bands except for band 6 (resolution of $120 \mathrm{~m}$; Zhao, 2003). Cloud cover has an important impact on the visual interpretation of TM images. Therefore, we selected three scene TM images under cloudless conditions on 10 September 2006. The datasets were obtained from the National Scientific Data Mirror Sites (http://www.gscloud.cn). The parameters of the cloudless images covered the MRB are listed in Table 1. To improve the accuracy of visual interpretation, we conducted a series of preprocessing steps, such as atmospheric correction, geometric correction and terrain correction. First, using the dark subtract provided in the atmospheric correction module of the ENVI 4.8 software, we converted the digital number $(\mathrm{DN})$ value to atmospheric top-level reflectivity. Second, we geometrically corrected the images based on the polynomial method. The overall error was within one pixel. Finally, we used the topographic correction module in ENVI 4.8 software to perform topographic correction to eliminate the irregular topography caused by the changes in brightness using Digital Elevation Model (DEM) data.

\subsubsection{DEM data}

The ASTER GDEM data were issued by the National Aeronautics and Space Administration and Ministry of Economy, Trade and Industry, using the geographical latitude and longitude coordinates system with a spatial resolution of $30 \mathrm{~m}$. Thus, we obtained the slope and aspect data from this dataset (http://www.gscloud.cn). 
Table 1 Parameters of the Landsat TM images covered the Manas River Basin (MRB)

\begin{tabular}{ccccc}
\hline Image date & $\begin{array}{c}\text { World Reference System 2 } \\
\text { (WRS-2) Path/Row }\end{array}$ & $\begin{array}{c}\text { Average cloud cover } \\
(\%)\end{array}$ & $\begin{array}{c}\text { Solar altitude angle } \\
\left({ }^{\circ}\right)\end{array}$ & $\begin{array}{c}\text { Solar azimuth } \\
\left({ }^{\circ}\right)\end{array}$ \\
\hline 10 September 2006 & $143-029$ & 0 & 46.80 & 150.68 \\
10 September 2006 & $143-030$ & 0 & 47.90 & 149.38 \\
10 September 2006 & $144-030$ & 10 & 45.63 & 151.66 \\
\hline
\end{tabular}

\subsection{Methods}

2.2.1 Snow cover extraction method

Various methods have been proposed for mapping snow cover based on different sensors (Yang et al., 2013). Algorithms for optical sensors with high or low spatial resolution are usually based on the NDSI. As shown in Eq. 1, NDSI takes advantage of the contrast between a visible wavelength and shortwave infrared of the snow spectral signature.

$$
\text { NDSI }=\left(\rho_{2}-\rho_{5}\right) /\left(\rho_{2}+\rho_{5}\right) \text {. }
$$

Where, $\rho_{2}$ and $\rho_{5}$ are the reflectivity of the TM band2 $(0.52-0.60 \mu \mathrm{m})$ and TM band5 $(1.55-1.75 \mu \mathrm{m})$, respectively.

This spectral index is used to enhance the snow and ice targets and distinguish them from vegetation, bare ground and most clouds. However, the NDSI index can not distinguish snow and snow-covered ice, or snow and bare ice. Therefore, snow-covered ice and bare ice were included in the results obtained from the NDSI.

The spectral responses of snow and clouds are very similar in visible and near-infrared bands. However, in SWIR bands, most clouds have a very high reflectance whereas the snow has a very low reflectance. Therefore, both targets can be differentiated in the SWIR bands.

Hall et al. (1995) indicated that a threshold of 0.4 applied to the NDSI is efficient for distinguishing snow and ice targets from other targets. However, water also has a high NDSI value because it can absorb almost all SWIR radiation. To clarify this result, additional criteria were applied to the apparent reflectance values at the top of the atmosphere in the algorithm.

Therefore, considering all of the factors, the criteria for snow and ice identification were: (1) an NDSI threshold (NDSI $>0.4)$; (2) water exclusion $\left(\rho_{4}>0.11\right.$; $\rho_{4}$ is the reflectivity of TM band4); and (3) dark pixel exclusion $\left(\rho_{2}>0.1\right)$.

\subsubsection{Visual interpretation method}

Currently, visual interpretation is believed to be the best way to effectively obtain land use classes. In the present study, we obtained the land use types based on the platform of ArcView software combined with DEM. The technological process mainly included the following three parts. (1) Classification system of objects was defined firstly, and the typical sample areas to be interpreted were selected. Then, in terms of the image characteristics, including color, shape, size, texture and shadow, the interpretive marks were established. (2) According to the interpretation principles and steps, we operated the interior interpretation. Based on the interpretive marks, and the methods of direct judgment, comparative analysis and integrative reasoning, we discussed the interpretation of images in detail and then determined the land use boundary and classes. (3) For evaluating the interpretation, we conducted a field investigation and used the data for testifying and correcting the results.

\subsubsection{Methods to measure uncertainty}

The uncertainty expression of remote sensing data classification is closely related to its evaluation, and the former is a part of the latter one (Congalton, 1994). From the perspective of the current evaluation methods, the accuracy assessment methods are classified as error matrix and fuzzy evaluation. Among them, the error matrix is the core method of the current evaluation systems and is recommended as the standard assessment method (Smits et al., 1999). However, the accuracy method based on error matrix has limitations, such as the inability to present the classification uncertainty at the pixel scale (Goodchild et al., 1992). Therefore, classification uncertainty indices based on the posterior probability vector were developed, such as absolute uncertainty, relative uncertainty, the extent of mixed pixel level, rough entropy and roughness. In this study, roughness and error matrix methods were 
used as the evaluation methods.

The error matrix summarizes the relationship between two datasets, often including classification map and reference test information (Congalton et al., 1991). In this study, they were snow cover map and land cover map, respectively. The error matrix clearly presents the included and omitted errors of different categories and by which we can calculate the overall accuracy (OA), producer's accuracy and user's accuracy. Another discrete multivariate index used in accuracy assessments is Kappa $(\mathrm{K})$ coefficient. The OA and $\mathrm{K}$ statistics can be calculated as Eq. 2 and Eq. 3, respectively (Wei et al., 2010).

$$
\begin{gathered}
\mathrm{OA}=\frac{\sum_{i=1}^{k} n_{i i}}{n}, \\
\mathrm{~K}=\frac{n \sum_{i=1}^{k} n_{i i}-\sum_{i=1}^{k} n_{i+} n_{+i}}{n^{2}-\sum_{i=1}^{k} n_{i+} n_{+i}} .
\end{gathered}
$$

Where, $n$ is the total number of observations; $k$ is the number of rows in the matrix; $n_{i i}$ is the number of observations in row $i$ and column $i ; n_{i+}$ and $n_{+i}$ are the total numbers of pixels in $i$-th row and $i$-th column, respectively.

Rough set theory (Pawlak, 1997) is a method that can be employed to analyze the uncertainty systems. In this study, it was applied to the uncertainty system of remote sensing images so that an index (i.e. roughness) can be obtained to assess the uncertainty. The effects of the spatial resolution of sensor and spatial scales of surface characteristics were only approximately expressed because we cannot obtain the proportional and non-discriminatory features using remote sensing technology. Therefore, the lower approximation (LA) $\underline{B} X$ and upper approximation (UA) $B X$ of rough set theory were used to express these effects. LA is defined as the pixel set of the corresponding category that has a component value of one in the probability vector; UA is the pixel set of the category that has a value greater than zero. The set $\underline{B} X$ is a maximal set including objects that can be certainly classified as elements of $X$, while $B X$ is a minimal set of objects which can be possibly classified to $X$ ( $\mathrm{Li}$ et al., 2006). Thus, the roughness of the set $X$ is defined as Eq. 4 .

$$
\rho_{\mathrm{A}}(X)=1-|\underline{B} X| /|B X| \text {. }
$$

Therefore, the value of $\rho_{A}(X)$ is less than or equal 1 and greater than or equal 0 . If $\rho_{\mathrm{A}}(X)$ is much closer to 0 , then the uncertainty of the rough set $X$ is much smaller.

Additionally, we introduced a parameter to easily describe the difference of snow cover extraction based on the visual interpretation and NDSI methods in various elevation zones. The parameter is defined as follows.

$$
\text { Per }=\frac{\left|A_{N}-A_{R}\right|}{A_{R}} \text {. }
$$

Where, Per is the ratio of the residual snow-covered area (the difference between $A_{N}$ and $A_{R}$ ) to the actual snow-covered area, $A_{N}$ is the snow-covered area extracted by the NDSI method and $A_{R}$ is the corresponding area by the visual interpretation method. With the increase of Per value, the error (uncertainty) of snow cover extraction based on NDSI increases. In contrast, the uncertainty of snow cover extraction decreases.

\section{Results and discussion}

\subsection{Sample area}

To efficiently determine the uncertainty of snow cover extraction, we selected three $6 \mathrm{~km} \times 6 \mathrm{~km}$ areas in the $\mathrm{MRB}$ as typical sample areas (i.e. A, B and C; Fig. 2) based on the terrain and land cover distribution. We obtained the snow distribution maps of the three sample areas by using the NDSI and visual interpretation methods (Fig. 2). Then, we concluded that difference in snow cover extraction based on NDSI and visual interpretation existed, which were significant in the snow boundary and shadowy areas.

\subsection{Uncertainty of snow cover extraction caused by terrain factors}

Distribution differences in snow depths of different elevation zones caused the sensors to receive various amounts of radiant energy, which affected the accuracy of snow cover extraction (Lin et al., 2012). Because of the significant differences in solar radiation energy received by the pixels of different aspects and slopes, some pixels were in shadow whereas others were excessively photosensitive. Thus, uncertainty was generated when extracting the snow information. This research explored the uncertainties of snow cover extraction caused by the elevation, slope and aspect using the NDSI method. 


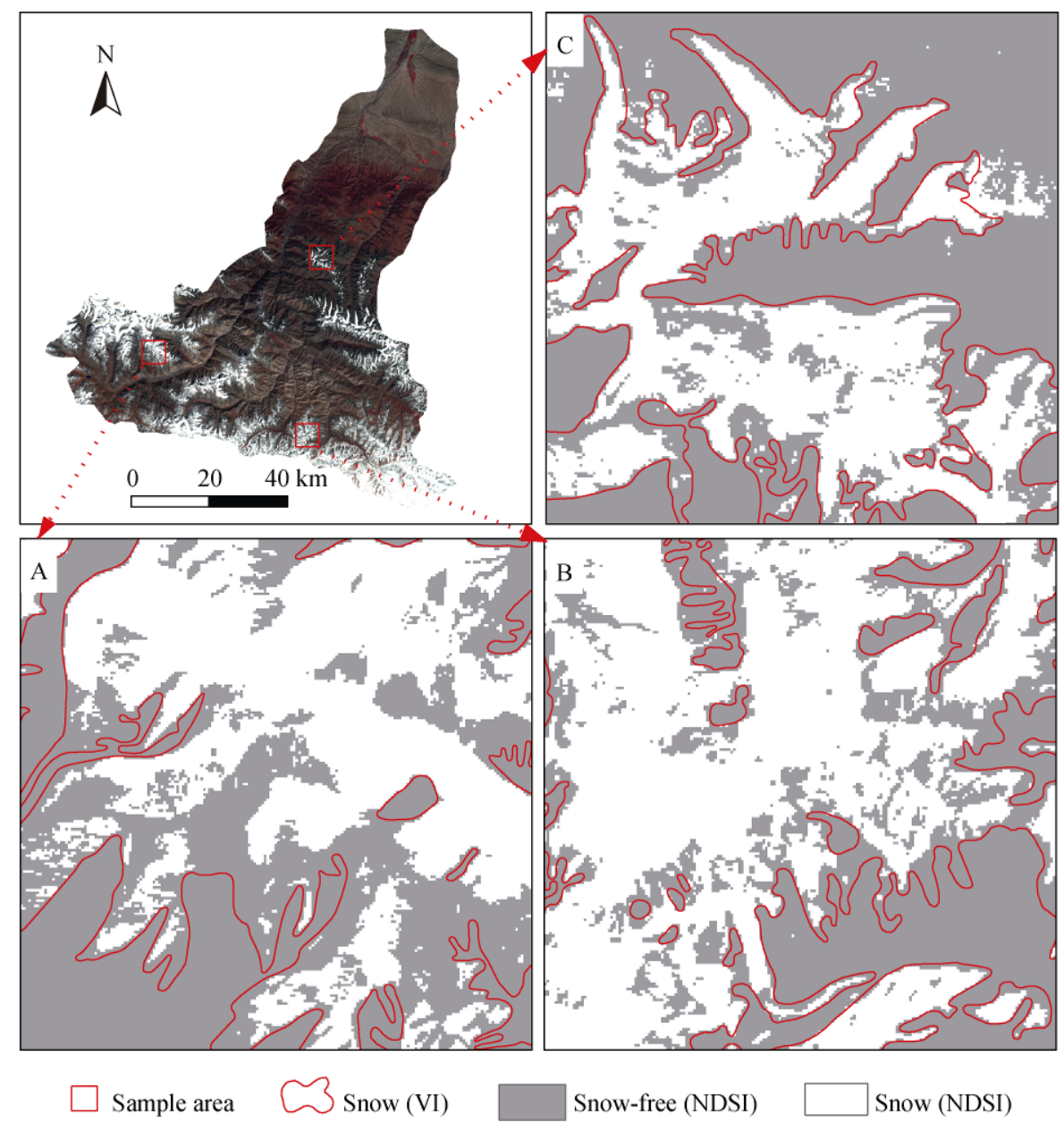

Fig. 2 Snow maps of the sample areas based on visual interpretation (VI) and Normalized Difference Snow Index (NDSI)

\subsubsection{Elevation}

To discuss the impact of elevation on snow cover extraction, we divided the MRB into six elevation zones, i.e. $<2,700,2,700-3,200,3,200-3,700,3,700-4,200$, $4,200-4,700$ and $\geq 4,700 \mathrm{~m}$ (Fig. $3 \mathrm{a}$ ), based on the summary of integrated natural divisions of Xinjiang (Yang, 1987). We analyzed the relationship between snow-covered areas and various elevation zones. Two methods of detecting snow-covered areas in different elevation zones were summarized and the Per value was calculated (Fig. 3b). Then, we obtained the mean Per value $(28.20 \%)$. Thus, the total accuracy of snow cover extraction using NDSI method is $71.80 \%$, which indicates that using the NDSI method for snow cover extraction is reliable. However, significant differences existed in snow-covered areas of various elevation zones, which indicated that elevation had a great ef- fect on snow cover extraction when using the NDSI method. For the altitudes of 3,700-4,200 m, the Per was maximum with the value of $38.75 \%$, which indicated that the error of snow cover extraction from using the NDSI method was relatively high and greater uncertainty existed in this elevation zone. However, the Per had a minimum value of $12.89 \%$ in the elevation zone of 4,700-5,300 m, which indicated that the uncertainty of snow information extraction was low in this elevation zone.

Overall, the tendency of the Per value was normally distributed with the increase of altitude (Fig. 3b). That is, Per value increased first and then decreased rapidly as the altitude increased. According to the study of $\mathrm{Li}$ et al. (2011), the area with the elevation above 4,100 $\mathrm{m}$ is the stable snow-covered area in which the coefficient of variation during the year is relatively small. 

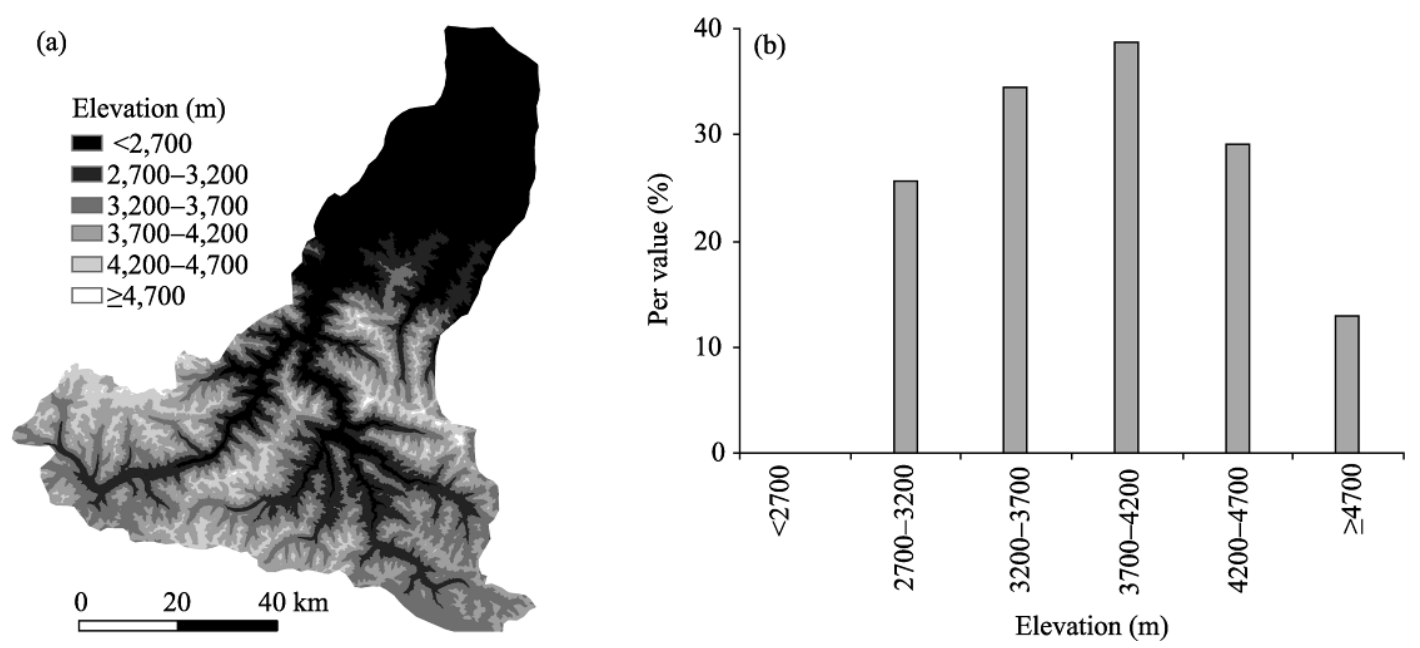

Fig. 3 Elevation zone map (a) and the Per values along with the elevations (b) in the MRB. Per is the ratio of the difference between snow-covered area extracted by the Normalized Difference Snow Index (NDSI) method and visual interpretation method to the actual snow-covered area.

In contrast, the coefficient of variation in the seasonal snow-covered area (below 3,600 m) is large. In this study, we found that the uncertainty of snow cover extraction in the seasonal snow-covered area increased as the altitude increased based on the NDSI method. However, the uncertainty of snow cover extraction in the stable snow-covered area decreased rapidly as the altitude increased.

\subsubsection{Slope}

We obtained the slope map and divided the slope into six categories at $10^{\circ}$ intervals based on the DEM. Then, combining with the snow cover maps that were obtained from the visual interpretation and NDSI methods, we extracted snow information of the three sample areas. The statistical results of the snow information at each slope are listed in Table 2 . When the slope is between $30^{\circ}$ and $40^{\circ}$, the snow distribution area is the largest in each sample area (over $60 \%$ of the entire area). However, when the slope is greater than $60^{\circ}$, the snow coverage is very small.

To further analyze the effects of slope on snow cover extraction using the NDSI method, we calculated the roughness at each slope interval (Fig. 4). The roughness decreased with the increase of slope gradient in the three sample areas. Thus, the uncertainty of snow cover extraction decreased as the slope increased. This result was mainly due to the discrepancy in the atmospheric conditions of different slopes. The atmospheric transmittance was higher in the steep regions (Yang et al., 1987), which led to the discrepancy in the snow reflectivity of different slopes. The snow was brighter in areas with higher slopes.

\subsubsection{Aspect}

We created a aspect map based on the DEM and divided the aspect into eight categories: the north $\left(\mathrm{N} ; 0^{\circ}-22.5^{\circ}\right.$, $\left.337.5^{\circ}-360^{\circ}\right)$, northeast $\left(\mathrm{NE} ; 22.5^{\circ}-67.5^{\circ}\right)$, east (E; $67.5^{\circ}-112.5^{\circ}$ ), southeast (SE; $\left.112.5^{\circ}-157.5^{\circ}\right)$, south (S; $\left.157.5^{\circ}-202.5^{\circ}\right)$, southwest $\left(\mathrm{SW} ; 202.5^{\circ}-247.5^{\circ}\right)$,

Table 2 Snow information of various slopes in each sample area extracted by the visual interpretation and NDSI methods

\begin{tabular}{ccccrrrrc}
\hline Sample area & Method & $0^{\circ}-10^{\circ}$ & $10^{\circ}-20^{\circ}$ & $20^{\circ}-30^{\circ}$ & $30^{\circ}-40^{\circ}$ & $40^{\circ}-50^{\circ}$ & $50^{\circ}-60^{\circ}$ & $60^{\circ}-70^{\circ}$ \\
\hline \multirow{2}{*}{ A } & VI & 586 & 5,262 & 10,552 & 10,150 & 3,610 & 332 & 0 \\
& NDSI & 140 & 2,020 & 5,710 & 6,820 & 2,504 & 231 & 0 \\
\multirow{2}{*}{ B } & VI & 440 & 5,100 & 11,389 & 12,504 & 1,290 & 0 & 0 \\
& NDSI & 215 & 2,536 & 8,736 & 9,785 & 1,017 & 0 & 0 \\
& VI & 566 & 3,752 & 5,954 & 6,734 & 2,206 & 714 & 158 \\
C & NDSI & 317 & 2,167 & 4,244 & 4,998 & 1,688 & 594 & 139 \\
\hline
\end{tabular}

Note: The unit of snow information is pixel numbers. VI, visual interpretation; NDSI, Normalized Difference Snow Index. 


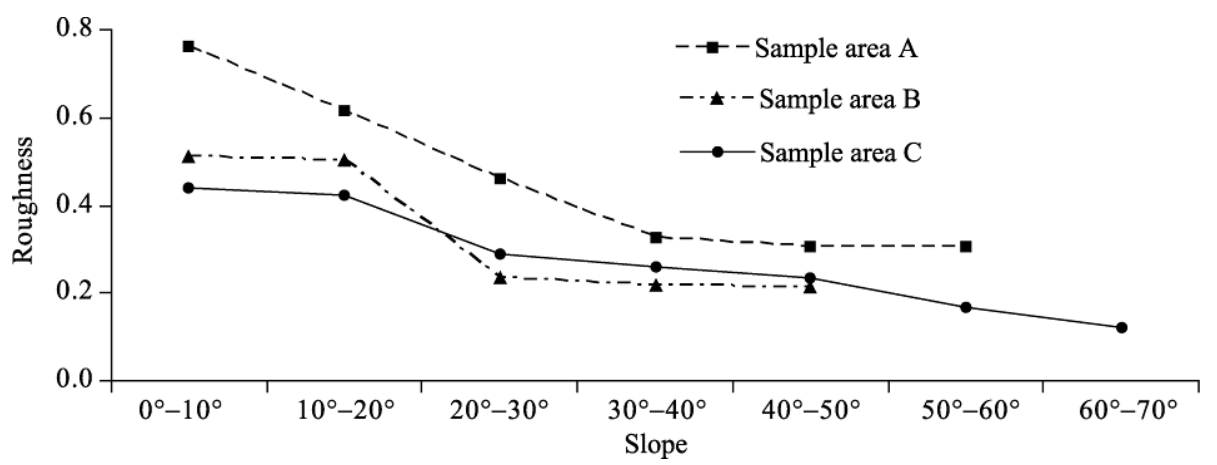

Fig. 4 Roughness of various slopes in each sample area

west (W; $\left.247.5^{\circ}-292.5^{\circ}\right)$ and northwest (NW; $292.5^{\circ}-337.5^{\circ}$ ) slopes. Among them, the north, northeast and northwest slopes were classified as shady slope; the south, southwest and southeast slopes were sunny slope; and the remaining slopes were semi-shady and semi-sunny slope. Using the aspect map and snow cover maps, we extracted the snow information (snow pixels) in the three sample areas (Table 3). The result showed that snow cover was mainly distributed on shady slope, and the snow-covered area in the north slope was the largest. Moreover, the snow-covered area in the south slope was the smallest, and the area in the remaining sunny slope was relatively small.

Further, we used the roughness of various aspects to further quantitatively analyze the effects of aspect on snow cover extraction (Fig. 5). The result indicated that the roughness (less than 0.32) was minimum in the northwest slope of each sample area; while the roughness values (average of 0.52 ) in the southwest, south and southeast slopes were significantly higher than the others. It is suggested that, aspects resulted in a magnitude uncertainty in snow cover extraction based on the NDSI method, and the impacts of different aspects on the uncertainty were as follows: sunny slope $>$ semi-shady and semi-sunny slope $>$ shady slope. The duration of solar radiation received by shady slope was relatively short, then the snow melted slower, resulting in the snow of this area had distinct spectral characteristics. All of these factors can reduce the uncertainty of snow cover extraction. In contrast, the sunny slope received more solar radiation and the snow of this area was lighter, which rendered the spectral characteristics of snow similar to that of bare land. Therefore, it was difficult to distinguish the snow boundary, and the uncertainty increased.

From the above analysis, we concluded that complex terrain factors can impact snow identification, specifically, the differences in elevations, aspects and slopes. These results were consistent with the conclusions of Wang (2012).

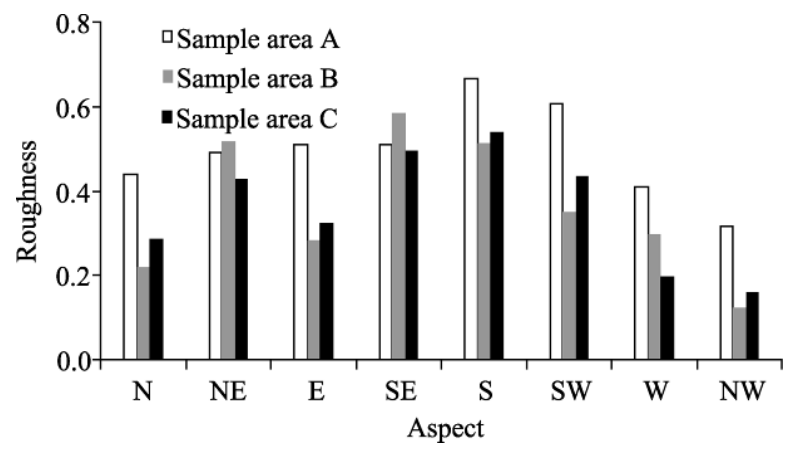

Fig. 5 Roughness of various aspects in each sample area

Table 3 Snow information of various aspects in each sample area extracted by the visual interpretation and NDSI methods

\begin{tabular}{cccccccccc}
\hline Sample area & Method & N & NE & E & SE & S & SW & W & NW \\
\hline \multirow{2}{*}{ A } & VI & 7,870 & 4,780 & 1,336 & 622 & 307 & 1,837 & 6,560 & 7,180 \\
& NDSI & 4,423 & 2,425 & 657 & 304 & 102 & 724 & 3,870 & 4,920 \\
& VI & 7,728 & 2,832 & 1,603 & 752 & 446 & 3,912 & 6,503 & 6,947 \\
B & NDSI & 6,044 & 1,365 & 1,152 & 313 & 217 & 2,539 & 4,576 & 6,083 \\
& VI & 4,927 & 3,027 & 1,385 & 428 & 254 & 2,583 & 2,942 & 4,538 \\
C & NDSI & 3,509 & 1,730 & 936 & 216 & 117 & 1,457 & 2,364 & 3,818 \\
\hline
\end{tabular}

Note: The unit of snow information is pixel numbers. 


\subsection{Uncertainty of snow cover extraction caused by land cover types}

To further understand the uncertainty and accuracy of snow cover extraction based on the NDSI, using a land cover map (the overall classification accuracy of $92.5 \%$ ) obtained by visual interpretation method using
Landsat TM images on 10 September 2006, we analyzed the effects of land cover types on snow identification and calculated the overall accuracy, misclassification rate, missing classification rate and Kappa coefficient to assess the accuracy. The results of statistics and accuracy analysis are shown in Table 4.

Table 4 Error matrix of snow information of each sample area under different land cover types and accuracy evaluation

\begin{tabular}{|c|c|c|c|c|c|}
\hline & & Glacier and snow & Middle coverage grassland & Shrub & Total \\
\hline \multirow{4}{*}{ Sample area A } & Snow pixel & $16,566(94.96 \%)$ & $879(5.04 \%)$ & 0 & 17,445 \\
\hline & Snow-free pixel & $4,694(20.70 \%)$ & $16,967(74.82 \%)$ & $1,017(4.48 \%)$ & 22,678 \\
\hline & Total & 21,260 & 17,846 & 1,017 & 40,123 \\
\hline & & \multicolumn{2}{|c|}{ Overall accuracy: $86.11 \%$} & ent: $76.08 \%$ & \\
\hline & & Glacier and snow & Bare rock & High coverage grassland & Total \\
\hline \multirow{5}{*}{ Sample area B } & Snow pixel & $18,752(83.89 \%)$ & $3,230(14.45 \%)$ & $370(1.66 \%)$ & 22,352 \\
\hline & Snow-free pixel & $4,877(27.43 \%)$ & $10,098(56.79 \%)$ & $2,806(15.78 \%)$ & 17,781 \\
\hline & Total & 23,629 & 13,328 & 3,176 & 40,133 \\
\hline & & Overall accuracy & \multicolumn{2}{|c|}{ Kappa coefficient: $63.77 \%$} & \\
\hline & & Glacier and snow & Bare rock & High coverage grassland & Total \\
\hline \multirow{4}{*}{ Sample area $\mathrm{C}$} & Snow pixel & $11,526(81.31 \%)$ & $2,649(18.69 \%)$ & 0 & 14,175 \\
\hline & Snow-free pixel & $1,280(4.93 \%)$ & $24,476(94.3 \%)$ & $199(0.77 \%)$ & 25,955 \\
\hline & \multirow[t]{2}{*}{ Total } & 12,806 & 27,125 & 199 & 40,130 \\
\hline & & Overall accuracy & \multicolumn{2}{|c|}{ Kappa coefficient: $79.39 \%$} & \\
\hline
\end{tabular}

There were five land cover types in the sample areas: glacier and snow, middle coverage grassland, high coverage grassland, shrub and bare rock. In the snow cover map of sample area A, 879 middle coverage grassland pixels were classified as snow incorrectly, and the misclassification rate was $5.04 \%$. Meanwhile, 4,694 snow pixels were missing, and the missing classification rate was $22.08 \%$. The overall accuracy was $86.11 \%$. In the sample area $\mathrm{B}$, some bare rock and high coverage grassland pixels were mistakenly identified as snow pixels (pixel numbers of 3,230 and 370 , respectively), and the total misclassification rate was $16.11 \%$. Furthermore, 4,877 snow pixels were classified as snow-free pixels, producing a missing classification rate of $20.64 \%$. Both of the overall accuracy and Kappa coefficient of sample area B were relatively low. In the sample area C, 2,649 bare rock pixels were incorrectly divided into snow pixels at a misclassification rate of $18.69 \%$. The missing classification rate is relatively lower at 1,280 missing pixels. Therefore, we concluded that the bare rock pixels were more likely to be misclassified. The overall accuracy and Kappa coefficient in the sample area $\mathrm{C}$ were $90.21 \%$ and $79.39 \%$, respectively.

The uncertainty of snow cover identification caused by land cover types revealed that bare rock had the greatest impact on snow cover extraction among all the land cover types in the study area, and the effect of shrub on snow cover recognition was smaller than that of grassland. The solar radiation received by different land cover types had obvious differences due to the influences of solar elevation angle, solar azimuth, atmospheric conditions and terrain factors ( $\mathrm{Li}$ et al., 2011). For example, if a large area of vegetation was mixed with snow, then the reflectance of the vegetation increased, resulting in the misclassification of vegetation pixels as snow. In shadowy areas, due to the low reflection of snow in TM band2, the snow and bare land cannot be correctly distinguished. Thus, the bare land pixels were classified incorrectly or missing, resulting in greater uncertainty.

The overall accuracy and Kappa coefficient of the 
sample area $\mathrm{B}$ with complex terrain were relatively lower than those of sample area $\mathrm{C}$ with only minor changes in topography. This was mainly because the regions with complex terrain can not efficiently receive solar radiation. These regions were likely to form shaded areas that caused the snow recognition accuracy to decrease and the uncertainty to increase. All of these findings indicated that the uncertainty caused by shaded areas was larger than that caused by mixed pixels when extracting snow-covered areas using the NDSI. Therefore, it was particularly important to effectively distinguish snow from snow-free in shaded areas by using the NDSI method.

\section{Conclusions}

After extracting the snow information based on the NDSI method and comparing it with the results from the visual interpretation method, the main conclusions were derived from the analysis and discussion of the uncertainties of snow cover extraction caused by the elevation, slope, aspect and land cover types.

(1) The uncertainty of snow cover extraction based on the NDSI method presented a general downward trend with the slope increased, due to the differences in the atmospheric conditions and reflectivities of various slopes.

(2) Because of the different durations of solar radiation received by each aspect, the snow thickness was deeper on the shaded slope while thinner on the sunny slope. By extracting snow information using the NDSI, the uncertainty of snow cover extraction of the sunny slope was greater than that of the semi-shady and semi-sunny slope. Moreover, the uncertainty of snow cover extraction of shady slope was the smallest.

(3) Significant differences existed in the Per values of various elevation zones. Per value $(38.75 \%)$ was largest at altitudes of 3,700-4,200 $\mathrm{m}$. Therefore, the uncertainty of snow cover extraction based on the NDSI method in this elevation zone was relatively high. However, uncertainty of snow cover extraction was relatively low in the elevations of 4,700-5,300 m.

(4) A large area of vegetation mixed with snow increased the reflectance of the vegetation, resulting in the misclassification of vegetation pixels as snow. In the shadowy areas, the uncertainty of snow cover ex- traction was greater because it was difficult to distinguish the snow and bare land correctly using the NDSI method.

(5) In the process of snow cover extraction, the only factors considered in this study were elevation, slope, aspect and land cover. The uncertainty associated with accessing remote sensing information, data preprocessing, thresholds and land surface temperature were not discussed. Further, this study only analyzed one phase of the image, and the land cover types were relatively simple. In future research, in addition to addressing the problems discussed in this study, we will use multi-stage remote sensing images to further analyze the uncertainty propagation principle and establish an uncertainty model to quantify and visualize the uncertainty based on uncertainty theory.

\section{Acknowledgments}

This work was funded by the National Natural Science Foundation of China (91025001) and the Key Project of the National Science and Technology (E0405/1112/05).

\section{References}

Arbia G, Griffith D, Haining R. 1999. Error propagation modeling in raster GIS: adding and rationing operations. Cartography and Geographic Information Science, 26(4): 297-316.

Chen X N, Bao A M. 2011. Snow cover change in Manas River Basin during 2007 and 2008, 1960 and 2006. Journal of Arid Land Resources Environment, 25(6): 154-160. (in Chinese)

Congalton R G. 1991. A review of assessing the accuracy of classifications of remotely sensed data. Remote Sensing of Environment, 37(1): 35-46.

Congalton R G. 1994. Accuracy assessment of remotely sensed data: future needs and directions. In: Proceedings of Pecora 12 Land Information from Space-based Systems. Bethesda: ASPRS, 383-388.

Congalton R G, Green K. 2008. Assessing the Accuracy of Remotely Sensed Data: Principles and Practices. Boca Raton: CRC Press, $1-183$.

Feng X Z, Li W J, Shi Z T, et al. 2000. Satellite snow cover monitoring and snowmelt runoff simulation of Manas River in Tianshan Region. Remote Sensing Technology and Application, 15(1): 18-21. (in Chinese)

Gahegan M, Ehlers M. 2000. A frame work for the modelling of uncertainty between remote sensing and geographic information systems. ISPRS Journal of Photogrammetry \& Remote Sensing, 55(3): 176-188.

Goodchild M F, Sun G Q, Yang S R. 1992. Development and test of error model for categorical data. International Journal of GIS, 6(2): $87-104$. 
GuoY J, Zhai P M, Li W. 2004. Snow cover in China derived from NOAA satellite remote sensing and conventional observation. Journal of Glaciology and Geocryology, 26(6): 755-760. (in Chinese)

Hall D K, Riggs G A, Salomonson V V. 1995. Developments of methods for mapping global snow cover using moderate resolution imaging spectoradiometer data. Remote Sensing of Environment, 54: 127-140.

Hao X H, Wang J, Li H Y. 2008. Evaluation of the NDSI threshold value in mapping snow cover of MODIS: A case study of snow in the Middle Qilian Mountains. Journal of Glaciology and Geocryology, 30(1): 132-138. (in Chinese)

Li H X, Feng X Z, Xiao P F. 2011. Satellite snow cover change analysis within the year of typical area in Tianshan Mountains. Remote Sensing Technology and Application, 26(3): 375-382. (in Chinese)

Li S P, Ge Y, Li D Y. 2006. Visualizing presentation of the attribute uncertainty in classified remotely sensed imagery. Remote Sensing For Land \& Resources, (2): 20-25. (in Chinese)

Lin J T, Feng X Z, Xiao P F. 2012. Inner-annual variation of snow cover in Mountainous Area of Manas Basin Based on MODIS. Remote Sensing Application, 25(2): 20-24. (in Chinese)

Liu Q H, Xin X Z, Tang P, et al. 2010. Quantitative Remote Sensing Model, Application and Uncertainty Research. Beijing: Science Press, 1-305. (in Chinese)

Lopez P, Sirguey P, Arnaud Y, et al. 2008. Snow cover monitoring in the northern Patagonia ice field using MODIS satellite images (2000-2006). Glob Planet Change, 61: 103-116.

Maguire D J, Goodchild M F, Rhind D W. 1991. Geographical Information Systems: Overview Principles and Applications. New York: Longman Scientific and Technical.

Pawlak Z. 1997. Rough set approach to knowledge-based decision support. International Journal of Computer and Information, 11: 48-57.

Sinton D. 1996. The inherent structure of information as a constraint to analysis: mapped thematic data as a case study. Harvard Papers on Geographic Information Systems, 6: 1-17.

Smits P C, Dellepiane S G, Schowengerdt R A. 1999. Quality assessment of image classification algorithms for land cover mapping: a review and proposal for a cost-based approach. International Journal of Remote Sensing, 20(8): 1461-1486.

Wang J. 1999. Comparison and analysis on methods of snow cover mapping by using satellite remote sensing data. Remote Sensing Technology and Application, 14(4): 29-36. (in Chinese)

Wang L X, Feng X Z, Xiao P F. 2011. Effect factors of satellite snow cover extraction in Manas River Basin, Xinjiang. Remote Sensing Information, (5): 31-37. (in Chinese)

Wang L X. 2012. Snow extraction in rugged mountain terrain of Manas River Basin. MSc Thesis. Nanjing: Nanjing University. (in Chinese)

Wei Y C, Tang G A, Yang X, et al. 2010. The Tutorial of Remote Sensing Digital Image Processing. Beijing: Science Press, 208-251. (in Chinese)

Xiao X, Shen Z, Qin X. 2001. Assessing the potential of vegetation sensor data for mapping snow and ice cover: a Normalized Difference Snow and Ice Index. International Journal of Remote Sensing, 22(13): 2479-2487.

Xiao X, Moore B, Qin X, et al. 2002. Large-scale observations of alpine snow and ice cover in Asia: Using multi-temporal vegetation sensor data. International Journal of Remote Sensing, 23(11): 2213-2228.

Yang J T, Jiang L M, Wu F M, et al. 2013. Monitoring snow cover over China with MTSAT-2 geostationary satellite. Journal of Remote Sensing, 17(5): 1264-1280.

Yang L P. 1987. Summary of Integrated Natural Divisions of Xinjiang. Beijing: Science Press, 47-48. (in Chinese)

Yuan G Y, Qu X L, Li J S. 1995. The protection and rational utilization of agricultural ecological environment of Manas River Basin in Xinjiang. Urumqi: Scientific and Technological Press, 1-20. (in Chinese)

Zhao Y S. 2003. Principles \& Methods of Remote Sensing Application and Analysis. Beijing: Science Press, 1-478. (in Chinese) 